\title{
Associations between disability-management self-efficacy, participation and life satisfaction in people with long-standing spinal cord injury
}

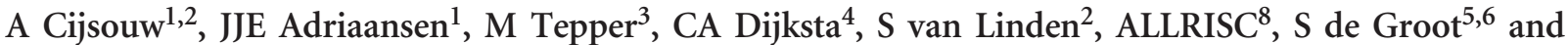 \\ MWM Post ${ }^{1,7}$
}

Objectives: To study disability-management self-efficacy (DMSE) and its correlates in a large sample of Dutch people with long-standing spinal cord injury (SCI). DMSE is the confidence that people with $\mathrm{SCl}$ may have in their ability to manage the consequences of their condition with respect to the various domains in their life. Research questions were: (1) What is the level of DMSE in Dutch people with long-standing SCI?; (2) Is DMSE associated with demographic and lesion characteristics?; and (3) IS DMSE associated with participation and life satisfaction if these associations are adjusted for demographic and lesion characteristics and mood?

Methods: Eligible people were identified from all eight rehabilitation centers with a specialty in $\mathrm{SCl}$ rehabilitation in the Netherlands $(N=261)$. Data were collected using a self-report questionnaire. DMSE was measured using the University of Washington Self-Efficacy Scale-Short Form (UW-SES-6). Correlation and linear regression analyses were used.

Results: Levels of UW-SES-6 scores were largely independent of demographic and lesion characteristics. UW-SES- 6 scores were bivariately moderately to strongly associated with mood (0.47), participation (0.39-0.51) and life satisfaction (0.46). In the regression analyses, UW-SES-6 scores still explained a significant amount of variance of participation (standardized $\beta$ 0.31-0.33) and life satisfaction (standardized $\beta$ 0.21) when controlling for demographic and lesion characteristics and mood, and explained an additional $3.2-8.1 \%$ of the variance of participation and life satisfaction.

Conclusion: DMSE is a psychological resource associated with higher levels of participation and life satisfaction after SCI. The UWSES-6 is a brief and easy to use measure of this psychological resource.

Spinal Cord (2017) 55, 47-51; doi:10.1038/sc.2016.80; published online 31 May 2016

\section{INTRODUCTION}

Approximately 500000 people suffer from a spinal cord injury (SCI) each year worldwide. ${ }^{1}$ SCI may result in loss of motor function, loss of sensation and is associated with a variety of secondary health conditions. Having an SCI is associated with participation restrictions and lower quality of life (QoL). ${ }^{2,3}$ Learning to cope with SCI is a challenging task and research shows that psychological characteristics of the people involved are important determinants of participation and QoL. ${ }^{4}$

A well-researched construct contributing to coping with disease and/or disability is self-efficacy (SE). SE is one's belief or sense of confidence in his/her own ability to perform a particular task or behavior in the future. ${ }^{5}$ High SE is considered a beneficial psychological resource as it enables a personal sense of control that facilitates the initiation of, and persistence in, adaptive behavior. High SE is consistently related with higher life satisfaction, greater psychological well-being, better mental health and less anxiety and depression in people with SCI. ${ }^{4,6}$

In the field of SCI, SE has mostly been measured as a general and stable characteristic of the individual. ${ }^{6}$ However, Bandura's definition of SE emphasizes that it should be measured in terms of particularized judgments of capability that may vary across activities and circumstances. ${ }^{7}$ Disability-management self-efficacy (DMSE) is the confidence that people with a chronic condition may have in their ability to manage the consequences of their condition with respect to the various domains of their life. ${ }^{8}$ The concept of DMSE is more specific to the circumstances of living with a disability, but is more general compared with SE with respect to isolated functional tasks, such as wheelchair driving and pressure sore prevention. ${ }^{9,10}$

Two measures have been developed to rate DMSE in people with SCI, the Moorong Self-Efficacy Scale (MSES) ${ }^{7}$ and the University of Washington Self-Efficacy Scale (UW-SES). ${ }^{8}$ The UW-SES has been

\footnotetext{
${ }^{1}$ Brain Center Rudolf Magnus and Center of Excellence in Rehabilitation Medicine, University Medical Center Utrecht and De Hoogstraat Rehabilitation, Utrecht, The Netherlands; ${ }^{2}$ Department of Clinical and Health Psychology, Utrecht University, Utrecht, The Netherlands; ${ }^{3}$ University Medical Center Groningen, Center for Rehabilitation, Groningen, The Netherlands; ${ }^{4}$ Department of Spinal Cord Injury Rehabilitation, De Hoogstraat Rehabilitation, Utrecht, The Netherlands; ${ }^{5}$ Amsterdam Rehabilitation Research Center, Reade, Amsterdam, The Netherlands; ${ }^{6}$ University of Groningen, University Medical Center Groningen, Center for Human Movement Sciences, Groningen, The Netherlands and ${ }^{7}$ University of Groningen, University Medical Center Groningen, Center for Rehabilitation, Groningen, The Netherlands

${ }^{8}$ Members of the ALLRISC are listed before References.

Correspondence: Professor MWM Post, Brain Center Rudolf Magnus and Center of Excellence in Rehabilitation Medicine, University Medical Center Utrecht and De Hoogstraat Rehabilitation, Rembrandtkade 10, 3583 TM Utrecht, The Netherlands.

E-mail: m.post@dehoogstraat.nl

Received 8 December 2015; revised 26 March 2016; accepted 6 April 2016; published online 31 May 2016
} 
shown to fit the Rasch model as a unidimensional hierarchical scale, ${ }^{8}$ whereas discrepant findings on the factor structure of the MSES have been reported. $7,11,12$

Regardless of the measure used, the construct of DMSE has been shown to be moderately to strongly correlated in the expected direction with measures of mood, mental health, social functioning, happiness and life satisfaction in people with SCI. ${ }^{7,8,11,13,14}$ Scores on both the MSES and UW-SES appear to be independent of age, level of education, duration of the SCI and level of SCI, ${ }^{8,11}$ but this has not been well investigated. Furthermore, most studies to date only reported bivariate associations between DMSE and QoL variables, or regression coefficients were only adjusted for age and gender. ${ }^{7,8,11,13}$ In all these studies, depressed mood was associated with SE and all other outcomes, and hence variation in mood may have been the common factor, thereby inflating the associations between disabilitymanagement SE and QoL variables. Only one study that included a measure of depression in their regression analysis showed an independent association between DMSE and autonomy in participation. ${ }^{14}$ Therefore, it remains unclear whether DMSE is an independent determinant of other participation and life satisfaction outcomes.

Hence, the aim of the current study was to study DMSE and its correlates in a large sample of Dutch people with long-standing SCI. Research questions were: (1) What is the level of DMSE in Dutch people with long-standing SCI?; (2) Is DMSE associated with demographic and lesion characteristics?; and (3) Is DMSE associated with participation and life satisfaction if demographic, lesion characteristics and mood are being controlled for?

\section{MATERIALS AND METHODS \\ Participants}

Data were used from the ALLRISC (Active LifestyLe Rehabilitation Interventions in aging Spinal Cord injury) study. ${ }^{15}$ Inclusion criteria were: living with SCI for at least 10 years; age at injury between 18 and 35 years; current age between 28 and 65 years and using a wheelchair, at least for longer distances $(>500 \mathrm{~m})$. This age range was chosen to include individuals with long-standing SCI while minimizing the effects of aging in general. Exclusion criterion was: insufficient mastery of the Dutch language to respond to an oral interview or to understand test instructions. Data were collected between November 2011 and February 2014. Only participants who completed the UW-SES (261 out of 282; $92.6 \%)$ were included in the current study.

\section{Procedure}

Eligible persons were identified through databases from all eight rehabilitation centers with a specialty in SCI rehabilitation in the Netherlands. They were invited to the center for the study by their attending rehabilitation physician. Patients were asked to complete the self-report questionnaire before visiting the center for a visit including a comprehensive check-up by the physician and physical tests and an oral interview by a trained research assistant. The research protocol was approved by the Medical Ethics Committee of the University Medical Center Utrecht. All participants gave written informed consent.

\section{Instruments}

DMSE was assessed using the short version of the UW-SES, the UW-SES- $6 .{ }^{8}$ Its six items concern the participants' confidence regarding the handling of potential negative consequences of their SCI. All items are scored on a 5-point scale (1: not at all; up to 5: completely). The UW-SES showed good psychometric properties with Cronbach's $\alpha$ of 0.90 and a high correlation coefficient (0.83) with the Chronic Disease Self-Efficacy Scale, and the UW-SES-6 explained $95 \%$ of the variance of the long version. ${ }^{8}$ With permission of the authors, the UW-SES- 6 was independently translated into Dutch by two experts (one rehabilitation physician and one psychologist) who compared their results and negotiated a consensus translation. The $t$-scores $(M=50$; s.d. $=10)$ were computed using the available transformation table. ${ }^{8}$ Cronbach's $\alpha$ of the UW-SES-6 in the current study was high (0.90) and principal components analysis showed only one component with an Eigenvalue exceeding 1 (3.96) and explaining $66 \%$ of the variance, supporting the unidimensionality of the Dutch UW-SES-6.

Mental health was measured with the Mental Health Inventory-5 (MHI-5), better known as the Mental Health scale of the Medical Outcome Study 36-item Short-Form (SF-36). ${ }^{16}$ The MHI-5 consists of five questions on mood during the past 4 weeks and showed validity in a cohort of people with SCI. ${ }^{17}$ The total MHI-5 score has a range from 0 (low mood) up to 100 .

Life satisfaction was measured with five items from the abbreviated World Health Organization Quality of Life (WHOQOL-BREF). ${ }^{18}$ The five items cover satisfaction with overall QoL and with health, daily activities, relationships and living conditions. All items are scored on a 5-point scale and the total score ranges between 5 (low life satisfaction) and 25 (high life satisfaction). The items together make up a valid scale. ${ }^{19}$

Participation was measured with the Utrecht Scale for Evaluation of Rehabilitation-Participation (USER-P). ${ }^{20,21}$ Two of the three subscales were used in the current study: experienced participation restrictions (11 items) and satisfaction with participation (10 items). The USER-P showed validity in an SCI population. ${ }^{22}$ Total scores of both scales range between 0 (lowest participation) and 100.

Demographic variables included were: age, gender, relational status (single versus stable relationship), nationality (Dutch versus other), having children, highest level of education achieved, employment status and living situation. Following Spinal Cord's guidelines for authors, age was categorized into 15-year increments $(<45 ; 46-60 ;>60$ years). Time since injury was grouped as $10-20$, $21-30,31-40$ and $>40$ years. Education was dichotomized into low education (primary school only, lower vocational education) and high education (high school, college, university). SCI characteristics were assessed by the physician as part of the study according to the International Standards for Neurological Classification of SCI. ${ }^{23}$ American Spinal Injury Association Injury Severity (AIS) grades $\mathrm{A}$ and $\mathrm{B}$ were categorized as motor complete lesions and AIS grades $\mathrm{C}$ and $\mathrm{D}$ as motor incomplete lesions.

\section{Data analyses}

Associations between the UW-SES-6 score and the other variables were examined using $t$-tests or analysis of variance for categorical variables and Pearson's correlation coefficients for continuous variables. Correlations of $<0.30$ were interpreted as weak, between 0.30 and 0.50 as moderate and of $\geqslant 0.50$ as strong. ${ }^{24}$ A series of hierarchical linear regression analyses were used to investigate associations between UW-SES-6 scores and participation and life satisfaction adjusted for confounders. In the first step of the statistical analysis the demographic and lesion characteristics were included, in the second step mood was included and in the third step the UW-SES-6 scores. Preliminary analyses to check for violations of the assumptions of normality, linearity, multicollinearity and homoscedasticity were performed. All analyses were performed using SPSS v22 (IBM, Armonk, NY, USA).

\section{RESULTS}

A total of 261 people, 192 males and 69 females, were included in the current analyses. Their characteristics are displayed in Table 1.

The mean total UW-SES-6 score was 47.5 (s.d.=9.7). The distribution was slightly positively skewed, but the skewness $(-0.14)$ and kurtosis $(0.37)$ were well within the limits of a reasonably normal distribution. Only $1.1 \%$ of the participants scored the lowest possible score (19.5) and $3.8 \%$ of the participants scored the highest possible score (69.0).

Responses to the six UW-SES-6 items are shown in Table 2. Participants rated their disability-management ability generally positively, although for each item a substantial proportion of the participants (16.8-35.6\%) expressed no or little DMSE.

Testing of differences in UW-SES-6 scores between subgroups based on demographic or lesion characteristics revealed no statistically 
significant differences with respect to age, time since injury, level and completeness of SCI and etiology of SCI (Table 3).

Multiple regression was conducted to further examine possible determinants of the UW-SES-6 scores. Age and time since injury were strongly intercorrelated $(r=0.85)$, and hence age was removed from the model to avoid multicollinearity. Only one independent variable, lesion level, made a unique significant contribution to the model (Table 4). The full model explained only $2.2 \%$ of the variance of UW-SES-6 scores.

Bivariate correlations between the UW-SES-6 scores and measures of participation restrictions (0.39), satisfaction with participation (0.51), mood (0.47) and life satisfaction (0.46) were moderate to strong and highly significant.

Hierarchical multiple regression showed DMSE to be an independent predictor of participation and life satisfaction in all analyses, explaining between 3.2 and $8.1 \%$ of the variation in addition to the variance explained by all other variables (Table 5).

Table 1 Characteristics of the study sample $(N=261)$

\begin{tabular}{|c|c|}
\hline Variable & \\
\hline Age (years), mean (s.d.); median; (range) & 48.5 (8.8); 47.9; (28.9-66.5) \\
\hline TSI (years), mean (s.d.); median; (range) & 24.1 (9.1); 22; (10-47) \\
\hline Gender ( $\%$ male) & 73.6 \\
\hline \multicolumn{2}{|l|}{ Etiology of injury ${ }^{a}(\%)$} \\
\hline Sports or leisure & 25.7 \\
\hline Violence & 1.5 \\
\hline Occupational & 10.7 \\
\hline Road traffic accident & 45.2 \\
\hline Fall & 9.2 \\
\hline Nontraumatic SCl & 9.6 \\
\hline Lesion level (\% tetraplegia) & 39.8 \\
\hline Completeness lesion ( $\%$ motor complete) & 81.6 \\
\hline Nationality (\% Dutch) & 96.2 \\
\hline Married or in stable relationship (\%) & 63.0 \\
\hline Education (\% low) & 27.6 \\
\hline Employment (\% paid employment) & 39.5 \\
\hline WHOQOL-5, mean (s.d.); (range) & $3.6(.7) ;(1.6-5)$ \\
\hline MHI-5, mean (s.d.); (range) & 79 (13.2); (26.7-100) \\
\hline USER-P restrictions, mean (s.d.); (range) & 76.4 (18.7); (24.2-100) \\
\hline USER-P satisfaction, mean (s.d.); (range) & 69.6 (15.2); (2.8-100) \\
\hline
\end{tabular}

Table 3 Distributions of the University of Washington Self-Efficacy Scale-Short Form (UW-SES-6) scores in relevant subgroups

\begin{tabular}{|c|c|c|c|c|c|}
\hline & $\mathrm{N}$ & $M$ & s.d. & $t / F$ & P-value \\
\hline Gender & & & & -0.42 & 0.674 \\
\hline Male & 192 & 47.3 & 9.9 & & \\
\hline Female & 69 & 47.9 & 9.1 & & \\
\hline Age (years) & & & & 0.23 & 0.795 \\
\hline $28-45$ & 109 & 47.9 & 11 & & \\
\hline $46-60$ & 125 & 47.3 & 8.7 & & \\
\hline$\geqslant 61$ & 27 & 46.6 & 8.6 & & \\
\hline Time since injury (years) & & & & 0.39 & 0.760 \\
\hline $10-20$ & 112 & 47.8 & 10.6 & & \\
\hline $21-30$ & 83 & 47.0 & 8.8 & & \\
\hline $31-40$ & 48 & 46.8 & 9.5 & & \\
\hline $41-47$ & 18 & 49.3 & 8.5 & & \\
\hline Completeness lesion & & & & -0.53 & 0.653 \\
\hline Motor complete & 213 & 47.4 & 9.9 & & \\
\hline Motor incomplete & 48 & 48.1 & 8.7 & & \\
\hline Lesion level & & & & -1.70 & 0.090 \\
\hline Tetraplegia & 104 & 46.3 & 10.1 & & \\
\hline Paraplegia & 157 & 48.4 & 9.3 & & \\
\hline Cause of injury & & & & 0.98 & 0.330 \\
\hline Traumatic & 236 & 47.7 & 9.7 & & \\
\hline Nontraumatic & 25 & 45.7 & 9.7 & & \\
\hline
\end{tabular}

DISCUSSION

In the present study, we described DMSE in people with SCI using a recently developed instrument, the UW-SES-6. Levels of DMSE were largely independent of demographic and lesion characteristics. Bivariate analysis showed that the DMSE was moderately to strongly associated with participation, mood and life satisfaction. In the regression analyses, DMSE explained a significant amount of the variance of participation and life satisfaction controlling for demographic and lesion characteristics and mood.

Demographic and lesion characteristics were not associated with MSE in this study, except for level of lesion, showing that people th less severe lesions reported slightly higher levels of DMSE. mever, the mean difference between people with paraplegia and wh tetraplegia was only 2.1 points, and this is small compared with the pooled s.d. of 9.6. Previous studies also showed not more than negligible associations between DMSE and demographic and lesion characteristics. ${ }^{8,11}$

Table 2 Distribution of scores on the short version of the University of Washington Self-Efficacy Scale (UW-SES-6)

\begin{tabular}{|c|c|c|c|c|c|}
\hline & Not at all & A little & Quite a bit & A lot & Completely \\
\hline \multicolumn{6}{|l|}{ How confident are you that } \\
\hline 1. You can keep the physical discomfort of your $\mathrm{SCl}$ from interfering with the things you want to do & $13.4^{\mathrm{a}}$ & 22.2 & 29.1 & 29.5 & 5.7 \\
\hline 2. You can keep your $\mathrm{SCl}$ from interfering with your ability to deal with unexpected events & 7.3 & 19.5 & 23.8 & 36.8 & 12.6 \\
\hline 3. You can keep your SCI from interfering with your ability to interact socially & 7.3 & 20.7 & 22.2 & 35.2 & 14.6 \\
\hline 4. You can keep your $\mathrm{SCl}$ from being the center of your life & 8.0 & 20.7 & 16.9 & 35.2 & 19.2 \\
\hline 5. You can bounce back from frustration, discouragement or disappointment that $\mathrm{SCl}$ may cause you & 3.4 & 13.4 & 21.5 & 41.4 & 20.3 \\
\hline 6. You can figure out effective solutions to SCl-related issues that come up & 2.3 & 15.7 & 25.3 & 40.2 & 16.5 \\
\hline
\end{tabular}


The relationship between DMSE and participation

As expected, we found positive associations between DMSE and participation. DMSE is a concept that holds relevance to participation as it refers to experienced control over living with SCI in daily and social life. Our findings are congruent with those of another recent study that found a similar correlation coefficient between DMSE and a measure of autonomy in participation. ${ }^{14}$ Participation of people with SCI is determined by a range of factors, including lesion characteristics and environmental factors. ${ }^{25}$ In the literature, similar associations between general SE and participation $(r 0.31-0.52)$ have been found. ${ }^{6,26}$

Table 4 Multiple regression analysis of potential determinants of University of Washington Self-Efficacy Scale-Short Form (UW-SES-6) scores

\begin{tabular}{lrcccc}
\hline Model & \multicolumn{1}{c}{$B$} & s.e. & $\beta$ & $t$ & P-value \\
\hline (Constant) & 43.80 & 3.07 & & 14.26 & 0.000 \\
Gender (female) & 0.39 & 1.39 & 0.02 & 0.278 & 0.782 \\
Time since injury & -0.00 & 0.07 & -0.00 & -0.03 & 0.973 \\
Lesion level (paraplegia) & 2.50 & 1.26 & 0.13 & 1.99 & 0.048 \\
Completeness (incomplete) & 1.71 & 1.61 & 0.07 & 1.06 & 0.289 \\
Cause of injury (nontraumatic) & -2.88 & 2.13 & -0.09 & -1.35 & 0.177 \\
\hline
\end{tabular}

Explained variance: $2.2 \%$.
The relationship between DMSE and mood and life satisfaction $\mathrm{SE}$ is one of the most consistent determinants of mood and life satisfaction in the literature, with associations between SE and QoL, life satisfaction and well-being ranging from $r=0.23$ to 0.73 , and $\beta=0.21$ to 0.39 . $^{4,6}$ The correlation coefficient of 0.46 between DMSE and life satisfaction found in our study corresponds well with these previous results. One other study used mood as a confounder and demonstrated DMSE to be an independent predictor of participation, but the authors did not report an association statistic. ${ }^{14}$ Another study used structural equation modeling to unravel associations between personal factors, participation and life satisfaction and also found a direct association between SE and life satisfaction, controlling for mood. ${ }^{27}$

\section{Limitations}

A limitation of the present study is that because of the inclusion criteria, our study sample predominantly consists of participants with a traumatic and complete SCI who had acquired their SCI at a relatively young age. This influences the degree to which the results of our study can be generalized to the whole population of people with SCI. Second, we used a Dutch translation of the UW-SES-6, but used the American conversion table to compute $t$-scores. Although the translation was carefully executed, the similarity of the Dutch and the American version needs confirmation. The score distributions in both studies are however fairly similar with a mean score of 47.5 (s.d. 9.7) in our study compared with 49.9 (s.d. 9.3) in the American sample. Finally, this is a cross-sectional study and hence no conclusions on causality can be drawn.

Table 5 Hierarchical multiple regression analyses of possible determinants of participation and life satisfaction

\begin{tabular}{|c|c|c|c|c|c|c|}
\hline \multirow[t]{2}{*}{ Model } & \multicolumn{2}{|c|}{ Participation restrictions } & \multicolumn{2}{|c|}{ Participation satisfaction } & \multicolumn{2}{|c|}{ Life satisfaction } \\
\hline & $\beta$ & $\mathrm{P}$-value & $\beta$ & $\mathrm{P}$-value & $\beta$ & $\mathrm{P}$-value \\
\hline \multicolumn{7}{|l|}{ Step 1} \\
\hline Gender (female) & -0.25 & $<0.001$ & 0.04 & 0.503 & 0.06 & 0.327 \\
\hline Time since injury & -0.07 & 0.205 & -0.07 & 0.287 & -0.02 & 0.752 \\
\hline Paraplegia & 0.49 & $<0.001$ & 0.19 & 0.003 & 0.09 & 0.143 \\
\hline Incomplete lesion & 0.05 & 0.375 & -0.01 & 0.841 & -0.02 & 0.744 \\
\hline Nontraumatic SCl & -0.03 & 0.028 & -0.06 & 0.372 & -0.10 & 0.142 \\
\hline$R^{2}$ ( $P$-value $)$ & $51.9 \%$ & $(<0.001)$ & $4.8 \%$ & $(0.028)$ & $2.3 \%$ & $(0.317)$ \\
\hline \multicolumn{7}{|l|}{ Step 2} \\
\hline Gender (female) & -0.27 & $<0.001$ & 0.01 & 0.794 & 0.03 & 0.569 \\
\hline Time since injury & -0.08 & 0.135 & -0.09 & 0.098 & -0.05 & 0.347 \\
\hline Paraplegia & 0.49 & $<0.001$ & 0.18 & 0.001 & 0.08 & 0.098 \\
\hline Incomplete lesion & 0.05 & 0.321 & -0.00 & 0.949 & -0.01 & 0.845 \\
\hline Nontraumatic SCl & -0.03 & 0.573 & -0.06 & 0.259 & -0.10 & 0.048 \\
\hline Mood & 0.23 & $<0.001$ & 0.51 & $<0.001$ & 0.62 & $<0.001$ \\
\hline$R^{2}$ change ( $P$-value) & $5.0 \%$ & $(<0.001)$ & $25.9 \%$ & $(<0.001)$ & $37.8 \%$ & $(<0.001)$ \\
\hline \multicolumn{7}{|l|}{ Step 3} \\
\hline Gender (female) & -0.26 & $<0.001$ & 0.02 & 0.737 & 0.03 & 0.534 \\
\hline Time since injury & -0.07 & 0.152 & -0.08 & 0.108 & -0.04 & 0.387 \\
\hline Paraplegia & 0.45 & $<0.001$ & 0.14 & 0.005 & 0.06 & 0.234 \\
\hline Incomplete lesion & 0.03 & 0.563 & -0.03 & 0.576 & -0.03 & 0.602 \\
\hline Nontraumatic SCl & -0.00 & 0.967 & -0.03 & 0.541 & -0.08 & 0.101 \\
\hline Mood & 0.08 & 0.183 & 0.35 & $<0.001$ & 0.52 & $<0.001$ \\
\hline DMSE & 0.31 & $<0.001$ & 0.33 & $<0.001$ & 0.21 & $<0.001$ \\
\hline$R^{2}$ change ( $P$-value) & $7.2 \%$ & $(<0.001)$ & $8.1 \%$ & $(<0.001)$ & $3.2 \%$ & $(<0.001)$ \\
\hline
\end{tabular}

Abbreviations: DMSE, disability-management self-efficacy; $R^{2}$, explained variance; $\mathrm{SCl}$, spinal cord injury. 


\section{Strengths}

This is the first SCI study using the UW-SES in people with SCI since its development. ${ }^{8}$ It is also one of the first studies to analyze associations between DMSE with participation and QoL variables accounting for mood as a confounder. In addition, data were utilized from a large sample that was recruited through all Dutch rehabilitation centers with a specialization in SCI rehabilitation in the Netherlands.

\section{Clinical implications}

The current study supports the concept of DMSE as an important determinant of participation and life satisfaction among people with SCI. DMSE may be seen as a psychological resource that helps people to regain their QoL after SCI. Low levels of SE may act as a notification for negative psychological profiles such as depressive mood or anxiety. Monitoring levels of SE among SCI patients is therefore desirable to be able to detect low levels of DMSE at an early stage. ${ }^{8}$ Interventions have been developed to increase SE with the goal of improving chronic disease outcomes. ${ }^{28}$ These interventions emphasize the patient's central role in managing his or her illness by providing patients with the necessary knowledge, skills and confidence (SE) to deal with the negative consequences of their chronic illness. ${ }^{13}$

\section{Future research}

Future studies may reveal the usefulness of the DMSE as a screener of psychological resources during rehabilitation and as an outcome of rehabilitation after SCI. Future research should also focus on effective approaches to enhance DMSE during and after rehabilitation.

\section{CONCLUSION}

DMSE is a psychological resource associated with higher levels of participation and life satisfaction after SCI. The UW-SES-6 is a brief and easy to use measure of this psychological resource.

\section{CONFLICT OF INTEREST}

The authors declare no conflict of interest.

\section{ACKNOWLEDGEMENTS}

ALLRISC is sponsored by 'Fonds NutsOHRA' under the responsibility of the Netherlands Organisation for Health Research and Development (www. ZonMW.nl), Project number 89000006.

\section{ALLRISC GROUP}

LHV van der Woude ${ }^{9}$, TWJ Janssen ${ }^{10}$, H Bussmann ${ }^{11}$, C Smit ${ }^{12}$, M Sloots ${ }^{12}$, D van Kuppevelt ${ }^{13}$, H Rijken $^{13}$, W Faber ${ }^{14}$, L Valent $^{14}$, G Snoek $^{15}$,

M Schuitemaker ${ }^{15}$, F Woldring ${ }^{16}, \mathrm{H}$ Bongers ${ }^{17}$, S Slangen ${ }^{17}$, M Wynants ${ }^{17}$, $\mathrm{T}_{\text {Sluis }}{ }^{18}, \mathrm{R}$ Broeksteeg ${ }^{18}$, P Luthart ${ }^{19}$

${ }^{9}$ University of Groningen, University Medical Center Groningen, Center for Human Movement Sciences, Center for Rehabilitation, Department of Rehabilitation Medicine, Groningen, The Netherlands; ${ }^{10}$ MOVE Research Institute Amsterdam, Faculty of Human Movement Sciences, VU University Amsterdam, The Netherlands; ${ }^{11}$ Department of Rehabilitation Medicine and Physical Therapy, Erasmus MC University Medical Centre, Rotterdam, The Netherlands; ${ }^{12}$ Amsterdam Rehabilitation Research Centre, Reade, Amsterdam, The Netherlands; ${ }^{13}$ Sint Maartenskliniek, Nijmegen, The Netherlands; ${ }^{14}$ Rehabilitation Center Heliomare, Wijk an Zee, The Netherlands; ${ }^{15}$ Roessingh Rehabilitation Center, Enschede, The Netherlands; ${ }^{16}$ University Medical Center Groningen, Center for Rehabilitation, Department of Rehabilitation Medicine, Groningen, The Netherlands; ${ }^{17}$ Adelante Zorggroep, Hoensbroek, The Netherlands; ${ }^{18}$ Rijndam Rehabilitation Center, Rotterdam, The Netherlands; ${ }^{19}$ Rehabilitation Center De Hoogstraat, Utrecht, The Netherlands.
1 Bickenbach J, Officer A, Shakespeare T, Von Groote P (eds). International Perspectives on Spinal Cord Injury. World Health Organization: Geneva, 2013.

2 Noreau L, Fougeyrollas P, Post MW, Asano M. Participation after spinal cord injury: the evolution of conceptualization and measurement. J Neurol Phys Ther 2005; 29: 147-156.

3 Post MW, van Leeuwen CM. Psychological issues in spinal cord injury: a review. Spinal Cord 2012; 50: 382-389.

4 van Leeuwen CMC, Kraaijeveld S, Lindeman E, Post MW. Associations between psychological factors and quality of life ratings in persons with spinal cord injury: a systematic review. Spinal Cord 2012; 50: 174-187.

5 Bandura A. Self-efficacy: toward a unifying theory of behavioral change. Psychol Rev 1977; 84: 191-215.

6 Peter C, Muller R, Cieza A, Geyh S. Psychological resources in spinal cord injury: a systematic literature review. Spinal Cord 2012; 5: 188-201.

7 Middleton JW, Tate RL, Geraghty TJ. Self-efficacy and spinal cord injury: psychometric properties of a new scale. Rehabil Psychol 2003; 48: 281-288.

8 Amtmann D, Bamer AM, Cook KF, Askew RL, Noonan VK, Brockway JA. University of Washington Self-Efficacy Scale: a new self-efficacy scale for people with disabilities. Arch Phys Med Rehabil 2012; 93: 1757-1765.

9 Fliess-Douer O, van der Woude LH, Vanlandewijck YC. Development of a new scale for perceived self-efficacy in manual wheeled mobility: a pilot study. J Rehabil Med 2011; 43: 602-608.

10 King RB, Porter SL, Vertiz KB. Preventive skin care beliefs of people with spinal cord injury. Rehabil Nurs 2008; 33: 154-162.

11 Miller SM. The measurement of self-efficacy in persons with spinal cord injury: psychometric validation of the moorong self-efficacy scale. Disabil Rehabil 2009; 31: 988-993.

12 Brooks J, Smedema SM, Tu W-M, Agle D, Catalano D, Chan F. Psychometric validation of the Moorong self-efficacy scale in people with spinal cord injury: a brief report. Rehabil Counsel Bull 2014; 58: 54-57.

13 Munce SE, Straus SE, Fehlings MG, Voth J, Nugaeva N, Jang E et al. Impact of psychological characteristics in self-management in individuals with traumatic spinal cord injury. Spinal Cord 2016; 54: 29-33.

14 Craig A, Nicholson Perry K, Guest R, Tran Y, Middleton J. Adjustment following chronic spinal cord injury: Determining factors that contribute to social participation. Br J Health Psychol 2015; 20: 807-823.

15 Adriaansen JJE, van Asbeck FWA, Lindeman E, van der Woude LHV, de Groot S, Post MWM. Secondary health conditions in persons with a spinal cord injury for at least 10 years: design of a comprehensive long-term cross-sectional study. Disabil Rehabil 2013; 35: 1104-1110.

16 Ware JE, Sherbourne CD. The MOS 36-itme short-form health survey (SF-36). I. Conceptual framework and item selection. Med Care 1992; 30: 473-483.

17 Van Leeuwen CMC, van der Woude LHV, Post MWM. Validity of the mental health subscale of the SF-36 in persons with spinal cord injury. Spinal Cord 2012; 50 : 707-710.

18 The WHOQOL Group. The World Health Organization Quality of Life Assessment (WHOQOL): development and general psychometric properties. Soc Sci Med 1998; 46 : 1569-1585.

19 Geyh S, Fellinghauer BAG, Kirchberger I, Post MWM. Cross-cultural validity of four quality of life scales in persons with spinal cord injury. Health Qual Life Outcomes 2010; 8: 94.

20 van der Zee CH, Kap A, Rambaran Mishre R, Schouten EJ, Post MW. Responsiveness of four participation measures to changes during and after outpatient rehabilitation. J Rehabil Med 2011;,43: 1003-1009.

21 Post MW, van der Zee CH, Hennink J, Schafrat CG, Visser-Meily JM, van Berlekom SB. Validity of the Utrecht scale for evaluation of rehabilitation-participation. Disabil Rehabil 2012; 34: 478-485.

22 Van der Zee $\mathrm{CH}$, Post MWM, Brinkhof MW, Wagenaar RC. Comparison of the Utrecht Scale for Evaluation of Rehabilitation-Participation with the ICF Measure of Participation and Activities Screener and the WHO Disability Assessment Schedule II in persons with spinal cord injury. Arch Phys Med Rehabil 2014; 95: 87-93.

23 Kirshblum SC, Burns SP, Biering-Sorensen F, Donovan W, Graves DE, Jha A et al. International standards for neurological classification of spinal cord injury (revised 2011). J Spinal Cord Med 2011; 34: 535-546.

24 Cohen J. Statistical Power Analysis for the Behavioural Sciences 2nd edn. Lawrence Erlbaum: Hillsdale, 1988.

25 Juvalta S, Post MW, Charlifue S, Noreau L, Whiteneck G, Dumont FS et al. Development and cognitive testing of the Nottwil Environmental Factors Inventory in Canada, Switzerland, and the USA. J Rehabil Med 2015; 47: 618-625.

26 Geyh S, Nick E, Stirnimann D, Ehrat S, Michel F, Peter C et al. Self-efficacy and selfesteem as predictors of participation in spinal cord injury - an ICF-based study. Spinal Cord 2012; 50: 699-706.

27 van Leeuwen CM, Post MW, Westers P, van der Woude LH, de Groot S, Sluis T et al. Relationships between activities, participation, personal factors, mental health, and life satisfaction in persons with spinal cord injury. Arch Phys Med Rehabil 2012; 93: 82-89.

28 Marks R, Allegrante JP, Lorig K. A review and synthesis of research evidence for self-efficacy-enhancing interventions for reducing chronic disability: implications for health education practice (part II). Health Promot Pract 2005; 6: 148-156. 